\title{
Research into biocompatibility and cytotoxicity of daptomycin, gentamicin, vancomycin and teicoplanin antibiotics at common doses added to bone cement
}

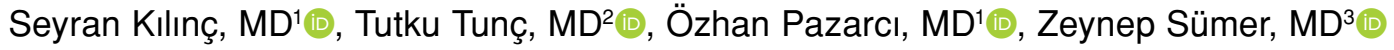 \\ ${ }^{1}$ Department of Orthopedics and Traumatology, Cumhuriyet University School of Medicine, Sivas, Turkey \\ ${ }^{2}$ Department of Pharmaceutical Sciences/Pharmaceutical Microbiology, Cumhuriyet University School of Medicine, Sivas, Turkey \\ ${ }^{3}$ Department of Microbiology, Cumhuriyet University School of Medicine, Sivas, Turkey
}

Infections head the list of major complications developing after orthopedic surgery, and many methods have been defined to deal with this complex complication. The addition of antibiotic to bone cement, i.e. polymethylmethacrylate (PMMA), is a commonly-used technique with many different methods. ${ }^{[1,2]}$ The application of PMMA with added antibiotics allows high concentrations of medication to be delivered directly to the infection region. ${ }^{[3,4]}$ Since the first use of antibiotics added to PMMA, there have been many articles published about this method. ${ }^{[1,5]}$

Pharmacologically, the addition of every antibiotic to cement is not appropriate. While the addition of antibiotics such as vancomycin and gentamicin to cement is common, due to increasing antibiotic resistance in recent years, newly-discovered antibiotics such as daptomycin have started to be added to cement. ${ }^{[6]}$ The type and dose of antibiotic to be added to cement should be chosen according to the profile and antibiogram of the organism. As

Received: March 19, 2020

Accepted: April 23, 2020

Published online: June 18, 2020

Correspondence: Seyran Kılınç, MD. Cumhuriyet Üniversitesi Tıp Fakültesi Ortopedi ve Travmatoloji Anabilim Dalı, 58140 Sivas, Türkiye.

E-mail: seyrankilinc@hotmail.com

Doi: $10.5606 /$ ehc. 2020.74943

Citation: Kılınç S, Tunç T, Pazarcı Ö, Sümer Z. Research into biocompatibility and cytotoxicity of daptomycin, gentamicin, vancomycin and teicoplanin antibiotics at common doses added to bone cement. Jt Dis Relat Surg 2020;31(2):328-334.

\section{ABSTRACT}

Objectives: This study aims to investigate the biocompatibility and cytotoxicity of daptomycin, gentamicin, vancomycin and teicoplanin at commonly-used dose intervals added to polymethylmethacrylate (PMMA) in vitro.

Materials and methods: This prospective study was conducted between February 2016 and June 2016. Antibiotics were added to PMMA at doses frequently used in clinical practice. The antibiotic doses added were teicoplanin $(2 \mathrm{~g}, 3 \mathrm{~g}, 4 \mathrm{~g})$, gentamicin $(0.5 \mathrm{~g}, 0.75 \mathrm{~g}, 1 \mathrm{~g})$, daptomycin $(0.5 \mathrm{~g}$.) and vancomycin ( $2 \mathrm{~g}, 3 \mathrm{~g}, 4 \mathrm{~g})$. Standard cement balls $(10 \mathrm{~mm})$ were created. Activated L929 mouse fibroblast cell culture was used for incubation. Agar diffusion, Cell Proliferation Kit II (XTT) test and electron microscope investigations were performed to examine biocompatibility and cytotoxicity.

Results: In the cytotoxicity test, teicoplanin at $4 \mathrm{~g}$ and daptomycin at $0.5 \mathrm{~g}$ doses were observed to cause reductions in viability percentages. The same doses caused $20 \%$ and $20-40 \%$ cell lysis indices during the agar diffusion test. On electron microscope images, cytotoxic effects in fibroblast cells and involvement with the surface of cement balls were observed.

Conclusion: Gentamicin, vancomycin and teicoplanin were observed to be non-toxic and biocompatible at commonly-used dose intervals. Teicoplanin at $4 \mathrm{~g}$ and daptomycin at $0.5 \mathrm{~g}$ doses were identified to be cytotoxic and not biocompatible. When selecting antibiotics to be added to bone cement, care should be taken that the antibiotic is non-toxic and biocompatible.

Keywords: Antibiotics, biocompatibility, bone cement, cytotoxicity, polymethylmethacrylate.

bone cement hardens with an exothermic reaction, some antibiotics are deactivated and therefore are not suitable for use in cement. ${ }^{[7]}$ Care should be taken that the chosen antibiotic is bactericidal, is in powder form to better integrate with the cement, is chemically/pharmacologically stable at high temperatures and is water soluble. ${ }^{[8,9]}$ In addition 
to the potential advantages of adding antibiotic to cement, there are some disadvantages, primarily allergic reactions, antimicrobial resistance and toxicity. ${ }^{[10]}$ Consequently, it is important to know the cytotoxicity and biocompatibility linked to dose of the antibiotics added into cement when administering treatment. In this study, we aimed to investigate the biocompatibility and cytotoxicity of daptomycin, gentamicin, vancomycin and teicoplanin at commonly-used dose intervals added to PMMA in vitro.

\section{MATERIALS AND METHODS}

This prospective study was conducted at the Cumhuriyet University School of Medicine between February 2016 and June 2016. All the methodology steps of the study are summarized in Table I. A total of $40 \mathrm{~g}$ antibiotic-free bone cement (twelve packets) were used in this study (Biofix cement ${ }^{\circledast}$, Chamberet, France). Each bone cement packet had teicoplanin (Sanofi Aventis Pharma ${ }^{\circledR}$, Istanbul, Turkey), daptomycin (Novartis Pharma $\mathrm{AG}^{\circledR}$, Basel, Switzerland), gentamicin (İbrahim Etem Ulagay İlaç, Istanbul, Turkey), and vancomycin (Mustafa Nevzat İlaç ${ }^{\circledast}$, Istanbul, Turkey) added at doses appropriate for clinical use. Standard samples were taken from each bone cement group. Sample groups are shown in Table I. The antibiotic doses added were teicoplanin $(2 \mathrm{~g}, 3 \mathrm{~g}, 4 \mathrm{~g})$, gentamicin $(0.5 \mathrm{~g}, 0.75 \mathrm{~g}, 1 \mathrm{~g})$, daptomycin (0.5 g.) and vancomycin ( $2 \mathrm{~g}, 3 \mathrm{~g}, 4 \mathrm{~g})$. These were added to the cement to form 10x10 $\mathrm{mm}$ balls in groups of as standard samples (Figures 1 and 2). Negative and positive controls of antibiotic-free PMMA were added to these groups. All experimental protocols were approved by the Cumhuriyet University Medical Faculty Ethics committee for non-interventional clinical research (approval: 21.01.2016-2016-01/05). The study was conducted in accordance with the principles of the Declaration of Helsinki.

L929 mouse fibroblast cells (Foot and Mouth Institute, Ankara, Turkey) frozen in dimethylsulfoxide (DMSO) and fetal bovine serum (FBS) (1/9 ratio) at $-80{ }^{\circ} \mathrm{C}$ were thawed to $37^{\circ} \mathrm{C}$. After washing with Dulbecco's Modified Eagle's Medium (DMEM) solution and centrifugation, they were placed in sterile flasks containing the medium (DMEM $+10 \%$ FBS $+1 \%$ penicillin-streptomycin). The samples were incubated at $37^{\circ} \mathrm{C}$ in a $5 \%$ carbon dioxide $\left(\mathrm{CO}_{2}\right)$ atmosphere. With viability falling to approximately $60 \%$ because of the freezing and thawing processes and the effect of DMSO, passages were performed for 7-10 days to increase the viability of fibroblasts to $95 \%$. When the cells reached $95 \%$ viability, they were trypsinized.
Media were refreshed every two days to remove toxic materials accumulating in the environment and proliferation processes were performed in many flasks to reach the number of cells required for the experiments.

The cells produced in flasks were transferred to six-well sterile plates at the rate of $1.5 \times 10^{5}$ cells $/ \mathrm{mL}$ in each well and incubated at $37^{\circ} \mathrm{C}$ for 24 hours in a $5 \% \mathrm{CO}_{2}$ incubator. When the cells fully covered the base of the wells, the medium above was changed and medium containing serum and melted agar (0.5$2 \%$ agarose by mass is appropriate for mammal cells) was added. When the agar solidified, the samples were investigated under an inverted light microscope (Nikon FDX-35, New York, USA) and then placed

\section{TABLO I \\ Methodology flowchart}

\section{Sample preparation}

- For each sample group including control groups, a total of 12 packets of 40 grams of bone cement were used

- Antibiotic doses were added to the cements in order

- Standard cement balls with $10 \mathrm{~mm}$ diameter were created for teicoplanin $(2,3,4 \mathrm{~g})$, daptomycin $(0.5 \mathrm{~g})$, gentamicin $(0.5,0.75,1 \mathrm{~g})$ vancomycin $(2,3,4 \mathrm{~g})$ and control groups

2. Cell culture preparation

- Activated L929 mouse fibroblast cells

- Fibroblasts proliferated in cell culture in sterile flasks

3. Agar diffusion test

- Cells incubated with $1.5 \times 10^{5}$ cells $/ \mathrm{mL}$ on sterile plates and cement balls added

- Negative and positive control samples prepared

- Wells stained with neutral red

- Microscope investigation of cell viability at 24 hours

4. Cytotoxicity test

- Cement balls incubated in tubes containing DMEM solution for one week

- Material filtrates placed on media

- $100 \mu \mathrm{L}$ of cement material filtrates added to cell cultures prepared on sterile plates

- Left for 24-hour and 72-hour incubation

- Cell viability percentages calculated with XTT test at 24 and 72 hours

5. Electron microscope analysis

- Two samples each taken from control group and investigation material

- Samples incubated in fibroblast cell cultures

- Prepared samples examined with SEM device at Erciyes University Technology and Research Center

DMEM: Dulbecco's Modified Eagle Medium; SEM: Scanning Electron Microscope; XTT: Cell Proliferation Kit II. 


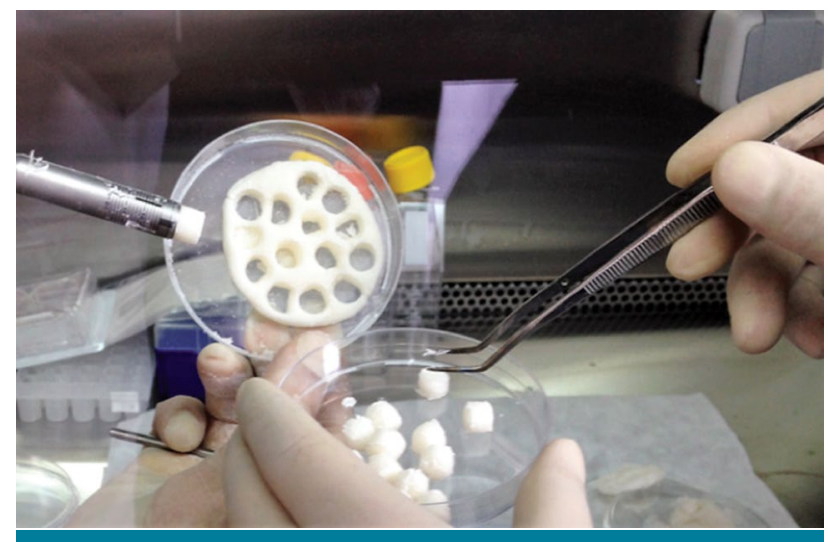

FIGURE 1. Preparation of standard $10 \times 10 \mathrm{~mm}$ bone cement samples.

in the center of the wells and left for incubation for 24 hours at $37^{\circ} \mathrm{C}$ under $5 \% \mathrm{CO}_{2}$ (Figure 3). Whatman paper (Whatman Ltd., Maidstone, Kent, UK) soaked in DMSO was used for negative control and DMEM for positive control. At the end of 24 hours, the vital stain of neutral red was dropped into the wells and cytotoxicity was determined with examination using the inverted microscope. The viability rates of the cells were identified according to the scale recommended by Ergün et al. ${ }^{[11]}$ (Table II).

As part of the cytotoxicity test:

a) The experimental material prepared under sterile conditions, i.e. the cement balls, were vortexed after being incubated in tubes containing $5 \mathrm{~mL}$ DMEM solution at $37^{\circ} \mathrm{C}$ for one week. Cement material filtrates obtained from each group were transferred to media, and then this filtrate was added to the fibroblast cell cultures prepared as follows: b) Cells covering the surface of flasks were trypsinized and placed in tubes containing medium (DMEM+FBS+PS). Separate 96-well sterile plates were used for the test, with each well on the plate applied with $1 \times 10^{4}$ cells medium distribution. The plates were left in a $5 \% \mathrm{CO}_{2}$ incubator for 24 hours at $37^{\circ} \mathrm{C}$, after which the medium was removed. Each well had $100 \mu \mathrm{L}$ medium added, then $100 \mu \mathrm{L}$ of each cement material filtrate was added. For positive control, medium-only wells were prepared and for negative control, wells containing alcohol and DMSO were prepared. Plates were incubated for 24 and 72 hours at $37^{\circ} \mathrm{C}$ in a $5 \%$ $\mathrm{CO}_{2}$ incubator.

c) After the processes above, plates prepared in 24 and 72 hours had the Cell Proliferation Kit II (XTT; Roche Diagnostics, Mannheim, Germany) test performed as follows: the prepared XTT (2,3-bis(2methoxy-4-nitro-5-sulfophenyl)-2H-tetrazolium-5carboxanilide) solution of $20 \mu \mathrm{L}$ was distributed to each well. After two-four hours duration, assessment was performed with an enzyme-linked immunosorbent assay (ELISA) optical reader at $450 \mathrm{~nm}$. The values obtained with the optical reader were used in the formula and separate cell proliferation/viability percentages were calculated for the test material (Table III).

For scanning electron microscope (SEM) investigation, paired samples of the control group and investigation material were used. The material was placed on 24-well plates, and each well had fibroblast culture of $3 \times 10^{4}$ cells added. The plates were then incubated for 24 and 72 hours at $37^{\circ} \mathrm{C}$ in a $100 \%$ humid environment. During the incubation period, the medium was not changed. At the end of the 24- and 72-hour incubation periods, $0.1 \%$

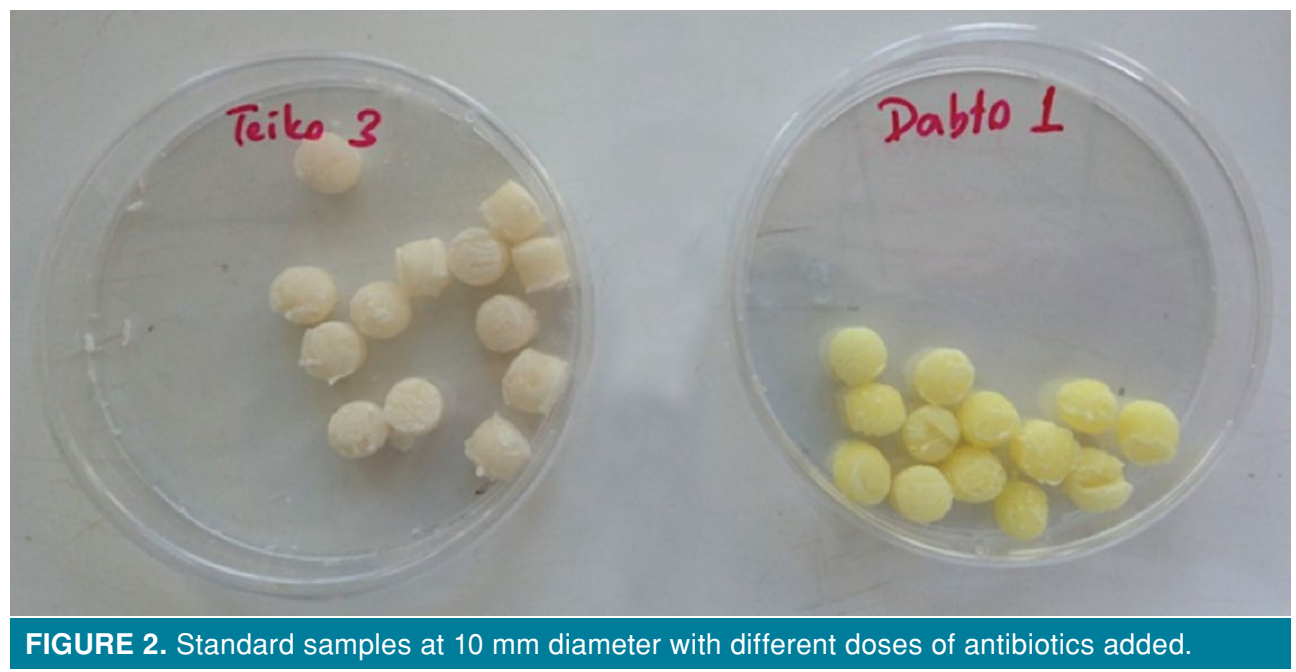




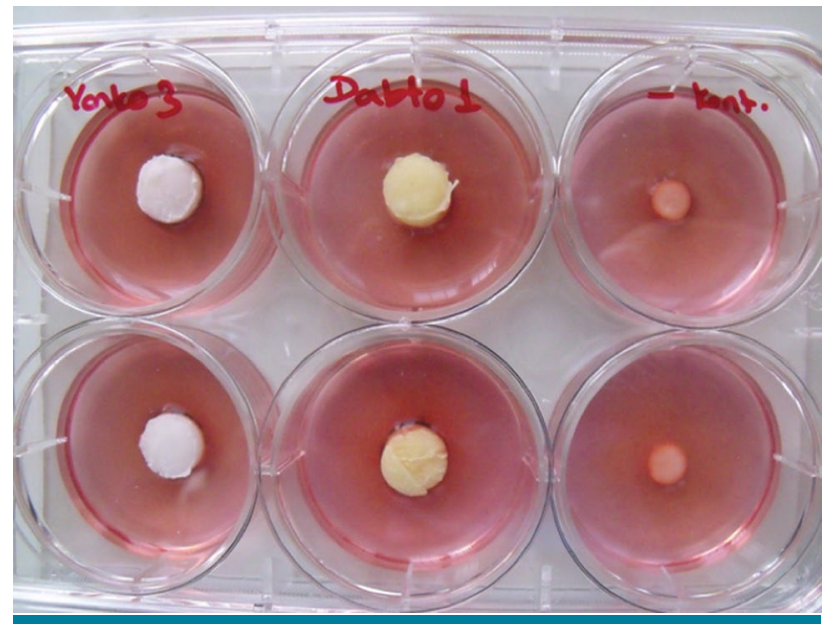

FIGURE 3. Samples prepared for agar diffusion test by placement in center of medium.

glutaraldehyde was used for 5-minute preliminary fixation. After aspiration of the media, sample discs were fixated in $4 \%$ glutaraldehyde for six hours, then washed with phosphate-buffered saline, and dehydrated with $50 \%, 60 \%, 70 \%, 80 \%, 90 \%$ and $95 \%$ ethyl alcohol series once each and pure ethyl alcohol twice. The samples were left for 10 minutes between each dehydration procedure. Later, the samples were sent to the SEM device (LEO 440 computercontrolled digital, Cambridge, England) in Erciyes University Technology and Research Center, where $\mathrm{CO}_{2}$ critical temperature drying processes were applied, after which the samples were covered with gold-palladium alloy and investigated (Figure 4).

\section{RESULTS}

According to the agar diffusion test results, visible lysis was not observed for gentamicin at $0.5 \mathrm{~g}, 0.75 \mathrm{~g}$ and $1 \mathrm{~g}$ doses, for vancomycin at $2 \mathrm{~g}, 3 \mathrm{~g}$, and $4 \mathrm{~g}$ doses and for teicoplanin at $2 \mathrm{~g}$ and $3 \mathrm{~g}$ doses. Teicoplanin at $4 \mathrm{~g}$ dose had $20 \%$ lysis observed in the area diameter. Daptomycin at $0.5 \mathrm{~g}$ dose had 20-40\% lysis observed (Table II).

The cytotoxic effect of the material on fibroblasts at 24 and 72 hours was assessed with calculations of data taken with an ELISA reader in the XTT test. The results were used to calculate mean cell proliferation percentages (Table III). Accordingly, the lowest 24-hour cell viability was observed for daptomycin. The highest decrease in cell viability at 72 hours compared to 24 hours was observed for teicoplanin $4 \mathrm{~g}$ dose. According to these results, daptomycin $0.5 \mathrm{~g}$ and teicoplanin $4 \mathrm{~g}$ doses were the most cytotoxic groups. Cytotoxicity was not observed for the other antibiotic groups.

The SEM investigations assessed fibroblast involvement and cells on the cement balls. Disintegrated fibroblast cells were observed with daptomycin $0.5 \mathrm{~g}$ dose and teicoplanin $4 \mathrm{~g}$ dose, due to the cytotoxic effect (Figure 4). Other images demonstrated that fibroblast cells had healthy adhesion to the surface.

\begin{tabular}{|c|c|c|c|}
\hline \multicolumn{4}{|c|}{$\begin{array}{l}\text { TABLE II } \\
\text { Ind agar diffusion test results }\end{array}$} \\
\hline & Sample name $(\mathrm{g})$ & Scale & Cell Lysis Index \\
\hline 1 & Gentamicin - 0.5 & 0 & No visible lysis \\
\hline 2 & Gentamicin - 0.75 & 0 & No visible lysis \\
\hline 3 & Gentamicin - 1 & 0 & No visible lysis \\
\hline 4 & Vancomycin - 2 & 0 & No visible lysis \\
\hline 5 & Vancomycin - 3 & 0 & No visible lysis \\
\hline 6 & Vancomycin - 4 & 0 & No visible lysis \\
\hline 7 & Teicoplanin - 2 & 0 & No visible lysis \\
\hline 8 & Teicoplanin - 3 & 0 & No visible lysis \\
\hline 9 & Teicoplanin - 4 & 1 & Lysis in $20 \%$ of the areal diameter \\
\hline 10 & Daptomycin - 0.5 & 2 & $20-40 \%$ lysis \\
\hline 11 & PMMA & 0 & No visible lysis \\
\hline 12 & Negative Control - DMSO & 4 & Lysis in $60-80 \%$ of the areal diameter \\
\hline 13 & Positive Control - DMEM & 0 & No visible lysis \\
\hline
\end{tabular}




\begin{tabular}{|c|c|c|c|}
\hline \multicolumn{4}{|c|}{$\begin{array}{c}\text { TABLE III } \\
\text { Cytotoxicity test results }\end{array}$} \\
\hline & Sample name (g) & $\begin{array}{c}\text { Cell viability } \\
\text { percentage } 24 \mathrm{~h}(\%)\end{array}$ & $\begin{array}{c}\text { Cell viability } \\
\text { percentage } 72 \mathrm{~h}(\%)\end{array}$ \\
\hline 1 & Gentamicin - 0.5 & 100 & 93 \\
\hline 2 & Gentamicin - 0.75 & 70 & 84 \\
\hline 3 & Gentamicin - 1 & 93 & 92 \\
\hline 4 & Vancomycin - 2 & 96 & 100 \\
\hline 5 & Vancomycin - 3 & 84 & 97 \\
\hline 6 & Vancomycin - 4 & 74 & 88 \\
\hline 7 & Teicoplanin - 2 & 100 & 100 \\
\hline 8 & Teicoplanin - 3 & 100 & 95 \\
\hline 9 & Teicoplanin - 4 & 100 & 77 \\
\hline 10 & Daptomycin - 0.5 & 60 & 58 \\
\hline 11 & PMMA & 88 & 87 \\
\hline 12 & Negative Control - DMSO & 0 & 0 \\
\hline 13 & Positive Control - DMEM & 100 & 100 \\
\hline
\end{tabular}

\section{DISCUSSION}

This study can be considered of value in terms of showing the cytotoxicity and biocompatibility of different antibiotics added to PMMA. Infection is a serious complication of orthopedic surgery, and when replacing implants or prosthesis removed because of infection, cement spacers with antibiotics added are commonly used. ${ }^{[12]}$ This application ensures that the dead cavity is filled after debridement of the infected region. ${ }^{[9,13]}$ Effective antibiotic release into the surgical field is important for protection from and treatment of infection. The main advantage of this technique is that local antibiotics reach concentrations that systemic treatment cannot reach. Although the amount of antibiotic within the cement is still a matter of debate, some authors have stated that a high dose of antibiotic should be used to increase the efficacy of the cement. ${ }^{[10,14]}$ To destroy bacterial colonization forming biofilm layers in cases with resistant infection, antibiotic concentrations need to be 100 times higher than standard concentrations. ${ }^{[15]}$ As increasing the antibiotic dose increases the local concentration, one of the aims of this study was to investigate the toxic effect on local tissues of the amount of dose increase. For surgeons, this raises the basic question of which antibiotic should be added to cement. Typing of the infection vector with culture is very important in the selection of the appropriate antibiotic. Moreover, with recent increases in antibiotic resistance, there is a need for variations in doses of antibiotics added to cements, the addition of new antibiotics to cement or different antibiotic release properties. ${ }^{[12,16]}$ However, the effects on healthy tissue when using these must be known. With this in mind, the current study investigated the cytotoxicity and biocompatibility of frequently-used doses of daptomycin, gentamicin, vancomycin and teicoplanin.

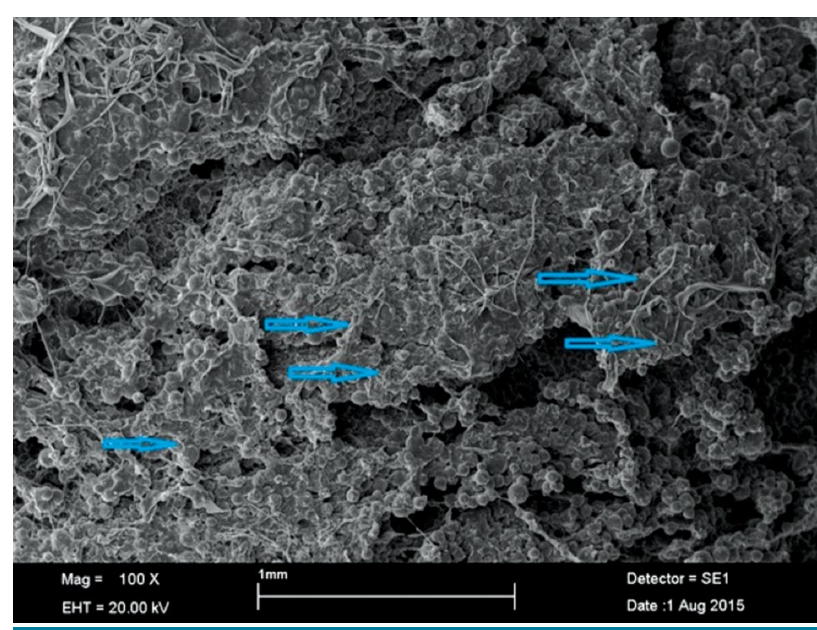

FIGURE 4. Scanning electron microscope image showing cytotoxic effect of daptomycin antibiotic at $0.5 \mathrm{~g}$ dose on fibroblasts (LEO 440 computer-controlled digital, Cambridge, England). Bone cement was of an intensified layered polymethylmethacrylate structure which was polymerized, and antibiotic particles were seen to exhibit regular distribution in a spherical morphology. Blue arrows show that fibroblasts still tend to grow in presence of antibiotic, but this had caused cell death by showing a toxic effect regionally. 
According to our best knowledge, the literature on the cytotoxicity and biocompatibility of these antibiotics is scarce. Previous studies have demonstrated that $400 \mathrm{mg}$ of teicoplanin in PMMA is biocompatible. ${ }^{[17]}$ In addition, negative effects of gentamycin and vancomycin on osteoblasts in certain doses have been emphasized in the literature. ${ }^{[18,19]}$ Our study also stands out in terms of examining these antibiotics participating in PMMA with their frequently used doses.

The agar diffusion test, XTT test and electron microscope investigation were used in this study. For the assessment of cytotoxicity of materials, the generally accepted criteria are cell death (viability tests), disrupted membrane integrity, reduced cell adhesion, variations in cell morphology and reduction in cell proliferation and biosynthetic/ enzymatic activity. ${ }^{[20]}$ The agar diffusion test is a barrier test method, which has long been in toxicity experiments. ${ }^{[21]}$ The formation of cellular injury results in loss of capacity of the cell to provide the energy required to maintain metabolic cell functions and growth, and thus sustain viability. The XTT test is a method based on this and generally measures mitochondrial activity. ${ }^{[22]}$ Electron microscope data ensured confirmation of these test results with visualization. That these three investigations were used together is a strong aspect of this study.

This study can be considered important in terms of investigating antibiotic groups at different doses commonly used in clinical practice, because antibiotics added to bone cement show dose-linked antibacterial effects. As the dose amount increases, the duration of antibiotic release from cement increases. ${ }^{[23]}$ Antibiotics added to PMMA must be resistant to the thermal effects of the cement, and have good water solubility. Consequently, the antibiotics that are suitable for addition to cement are limited. ${ }^{[14]}$ The surgeon should select the bone cement-antibiotic combination specific to the patient. The results of the current study are important in respect of showing the cytotoxicity and biocompatibility of a new antibiotic, such as daptomycin, in addition to routinely-used antibiotics.

The dose of daptomycin used in this study showed local toxic effects. In addition, daptomycin is a more expensive medication compared to other antibiotics, although the situation is such that in daily surgical practice, the use of daptomycin should be in compliance with benefit-harm calculations. This is because daptomycin is used for methicillinsensitive Staphylococcus aureus, methicillin-resistant
Staphylococcus aureus and vancomycin-resistant enterococci infections, which are difficult to treat and are resistant to other antibiotics. ${ }^{[2]}$ The use and efficacy of daptomycin combined cement spacers in arthroplasty infections caused by these vectors has been shown in previous studies. ${ }^{[25,26]}$ In the current study, local toxic effects were observed for daptomycin and teicoplanin at the stated doses on XTT, agar diffusion and electron microscope images.

All doses of gentamicin and vancomycin included in the study and teicoplanin at doses other than $4 \mathrm{~g}$ were shown to be biocompatible and non-toxic. This shows that there are minimal effects on surrounding soft tissue of antibiotics added to PMMA at these doses. Although teicoplanin was shown to be toxic at $4 \mathrm{~g}$ dose, the dose commonly used in clinical practice is lower, and higher doses may be used when the benefit-harm calculation is taken into consideration. ${ }^{[27-29]}$ This study is the first to show cytotoxicity and bio-incompatibility of teicoplanin at $4 \mathrm{~g}$ dose and daptomycin at $0.5 \mathrm{~g}$ dose. If these antibiotics are to be added to PMMA, the results of this study should be given consideration.

There were some limitations to this study. Although antibiotic doses commonly used in daily practice were included in the study, the dose of every antibiotic may be increased to toxic levels. This was an in vitro study, so properties of body fluids, movement of extremities, host response and in vivo antibiotic stability were not noted. There is a need for further studies to include different cell cultures, primarily osteoblast culture, which could be important in the evaluation of different tissue reactions for cytotoxicity and biocompatibility. In addition, to be able to broaden the antibiotic spectrum in the clinic, studies could be performed of different antibiotics added to the same PMMA. In the current study, each antibiotic was included separately. Further studies could show the effects of combinations on cytotoxicity.

In conclusion, although increasing the antibiotic dose in PMMA is known to increase the antibacterial effect, knowledge of the cytotoxicity that could form with the effect of increased doses could affect the treatment process. In this study, gentamicin, vancomycin and teicoplanin were observed to be non-toxic and biocompatible at the commonly-used dose intervals. Furthermore, with increasing doses, increases in cytotoxicity percentages were identified. Cytotoxicity was identified for $4 \mathrm{~g}$ teicoplanin dose and $0.5 \mathrm{~g}$ dose of daptomycin. When using antibioticloaded PMMA, which is one of our greatest weapons in the fight against infection, it was observed that an 
increased local dose could lead to cellular damage. The use of these antibiotics at high doses with bone cement should be limited to selected cases only after completing benefit-harm calculations.

\section{Acknowledgements}

The authors are grateful for the contribution of Dr. Ali Özer and Sivas Cumhuriyet University, R\&D Center, SEM Facility Lab. (CUTAM) in the evaluation of the SEM images.

\section{Declaration of conflicting interests}

The authors declared no conflicts of interest with respect to the authorship and/or publication of this article.

\section{Funding}

The authors received no financial support for the research and/or authorship of this article.

\section{REFERENCES}

1. Anagnostakos K, Fürst O, Kelm J. Antibiotic-impregnated PMMA hip spacers: Current status. Acta Orthop 2006;77:62837.

2. Issın A, Koçkara N. Simple method for increasing drug elution from polymethylmethacrylate bone cement. Eklem Hastalik Cerrahisi 2017;28:100-6.

3. Zimmerli W, Trampuz A, Ochsner PE. Prosthetic-joint infections. N Engl J Med 2004;351:1645-54.

4. Atıcı T, Şahin N, Çavun S, Özakin C, Kaleli T. Antibiotic release and antibacterial efficacy in cement spacers and cement beads impregnated with different techniques: In vitro study. Eklem Hastalik Cerrahisi 2018;29:71-8.

5. Buchholz HW, Engelbrecht H. Uber die Depot effects of various antibiotics mixed with Palacos resins. Chirurg 1970;41:511-5.

6. Jagadale V, Achilike R, Nord KM. Daptomycin-tobramycin cement beads have lethal local antibacterial effect in resistant periprosthetic joint infections. Cureus 2019;11:e5726.

7. Vaishya R, Chauhan M, Vaish A. Bone cement. J Clin Orthop Trauma 2013;4:157-63.

8. Küçükdurmaz F, Tuncay İ. Antibiyotikli çimento ve spacer uygulamaları. TOTBID Dergisi 2016;15:115-9.

9. Bistolfi A, Massazza G, Verné E, Massè A, Deledda D, Ferraris S, et al. Antibiotic-loaded cement in orthopedic surgery: a review. ISRN Orthop 2011;2011:290851.

10. Hendriks JG, van Horn JR, van der Mei HC, Busscher HJ. Backgrounds of antibiotic-loaded bone cement and prosthesis-related infection. Biomaterials 2004;25:545-56.

11. Ergün G, Sağesen L, Doğan A, Özkul A, Demirel E. Protez kaide materyallerinin sitotoksisitesinin agar difüzyon ve filtre difüzyon test yöntemleri ile incelenmesi. Gazi Üniversitesi Diş Hekimliği Fakültesi Dergisi 2006;23:31-7.

12. Bertazzoni Minelli E, Caveiari C, Benini A. Release of antibiotics from polymethylmethacrylate cement. J Chemother 2002;14:492-500.

13. Hanssen AD. Local antibiotic delivery vehicles in the treatment of musculoskeletal infection. Clin Orthop Relat Res 2005;437:91-6.

14. van de Belt $H$, Neut D, Schenk W, van Horn JR, van der Mei HC, Busscher HJ. Infection of orthopedic implants and the use of antibiotic-loaded bone cements. A review. Acta Orthop Scand 2001;72:557-71.

15. Nelson CL. The current status of material used for depot delivery of drugs. Clin Orthop Relat Res 2004;427:72-8.

16. Göçer H, Emir D, Önger ME, Dabak N. Effects of bone cement loaded with teicoplanin, $\mathrm{N}$-acetylcysteine or their combination on Staphylococcus aureus biofilm formation: an in vitro study. Eklem Hastalik Cerrahisi 2017;28:13-8.

17. Öztemür Z, Sümer Z, Tunç T, Pazarcé Ö, Bulut O. The effect of low dose teicoplanin-loaded acrylic bone cement on biocompatibility of bone cement. Acta Microbiol Immunol Hung 2013;60:117-25.

18. Ince A, Schütze N, Karl N, Löhr JF, Eulert J. Gentamicin negatively influenced osteogenic function in vitro. Int Orthop 2007;31:223-8.

19. Edin ML, Miclau T, Lester GE, Lindsey RW, Dahners LE. Effect of cefazolin and vancomycin on osteoblasts in vitro. Clin Orthop Relat Res 1996;333:245-51.

20. Pizzoferrato A, Ciapetti G, Stea S, Cenni E, Arciola CR, Granchi D, et al. Cell culture methods for testing biocompatibility. Clin Mater 1994;15:173-90.

21. Tunçel A, Ozdemir AK, Sümer Z, Hürmüzlü F, Polat Z. Cytotoxicity evaluation of two different composites with/ without fibers and one nanohybrid composite. Dent Mater J 2006;25:267-71.

22. Scudiero DA, Shoemaker RH, Paull KD, Monks A, Tierney S, Nofziger TH, et al. Evaluation of a soluble tetrazolium/ formazan assay for cell growth and drug sensitivity in culture using human and other tumor cell lines. Cancer Res 1988;48:4827-33.

23. Chang Y, Chen WC, Hsieh PH, Chen DW, Lee MS, Shih $\mathrm{HN}$ et al. In vitro activities of daptomycin-, vancomycin-, and teicoplanin-loaded polymethylmethacrylate against methicillin-susceptible, methicillin-resistant, and vancomycin-intermediate strains of Staphylococcus aureus. Antimicrob Agents Chemother 2011;55:5480-4.

24. Salehi A, Parker AC, Lewis G, Courtney HS, Haggard WO. A daptomycin-xylitol-loaded polymethylmethacrylate bone cement: how much xylitol should be used? Clin Orthop Relat Res 2013;471:3149-57.

25. Hsu YM, Liao CH, Wei YH, Fang HW, Hou HH, Chen $\mathrm{CC}$, et al. Daptomycin-loaded polymethylmethacrylate bone cement for joint arthroplasty surgery. Artif Organs 2014;38:484-92.

26. Rosslenbroich SB, Raschke MJ, Kreis C, Tholema-Hans N, Uekoetter A, Reichelt R, et al. Daptomycin: local application in implant-associated infection and complicated osteomyelitis. Scientific World Journal 2012;2012:578251.

27. Anagnostakos K, Meyer C. Antibiotic Elution from Hip and Knee Acrylic Bone Cement Spacers: A Systematic Review. Biomed Res Int 2017;2017:4657874.

28. Rouse MS, Piper KE, Jacobson M, Jacofsky DJ, Steckelberg JM, Patel R. Daptomycin treatment of Staphylococcus aureus experimental chronic osteomyelitis. J Antimicrob Chemother 2006;57:301-5.

29. Tuzuner T, Sencan I, Ozdemir D, Alper M, Duman $\mathrm{S}$, Yavuz $\mathrm{T}$, et al. In vivo evaluation of teicoplaninand calcium sulfate-loaded PMMA bone cement in preventing implant-related osteomyelitis in rats. J Chemother 2006;18:628-33. 